\title{
A fluorescent sensor for pyrophosphate based on a Pd(II) complex $\uparrow$
}

\author{
Received 6th May 2010, Accepted 3rd June 2010 \\ First published as an Advance Article on the web 25th June 2010 \\ DOI: $10.1039 / \mathrm{codt00434k}$
}

Jie Gao, ${ }^{a}$ Thomas Riis-Johannessen, ${ }^{b}$ Rosario Scopelliti, ${ }^{b}$ Xuhong Qian ${ }^{a}$ and Kay Severin*b

A mixture of the $\mathrm{Pd}(\mathrm{II})$ complex $\left[\mathrm{Pd}\left(\mathrm{NO}_{3}\right)_{2}\right.$ (bipy)] (bipy = 2,2'-bipyridine) and the fluorescent dye Methylcalcein blue (MCB) constitutes a chemosensing ensemble which can be used for the detection of pyrophosphate (PPi) by fluorescence spectroscopy. The sensor operates in buffered aqueous solution at neutral $\mathrm{pH}$, and allows sensing PPi at low to mid micromolar concentrations with very good selectivity over other anions such as phosphate, acetate, nitrate, sulfate, chloride, and bicarbonate.

\section{Introduction}

Pyrophosphate is a biologically important anion which is involved in numerous cellular processes. ${ }^{1}$ It is also used as an additive in food (E450), toothpaste, baking powder, and detergents. ${ }^{2}$ Not surprisingly, considerable efforts have been made to develop chemosensors for the optical detection of PPi. ${ }^{3}$ Most often, these sensors contain metal complexes as the recognition units. $\mathrm{Zn}$ (II) complexes are frequently used in this context, ${ }^{4}$ but other metal ions such as $\mathrm{Cu}(\mathrm{II}),{ }^{5} \mathrm{Cd}(\mathrm{II}),{ }^{6} \mathrm{Mn}(\mathrm{II}),{ }^{7} \mathrm{Eu}(\mathrm{III}),{ }^{8}$ and $\mathrm{Tb}(\mathrm{III})^{9}$ have been employed as well. Some of these sensors display remarkable sensitivity and selectivity. ${ }^{3}$ However, their preparation generally requires considerable synthetic efforts. Below we describe a Pd(II)based chemosensor, which can be obtained by dissolving easily available compounds in buffered aqueous solution. The sensor allows the selective detection of PPi by fluorescence spectroscopy.

\section{Results and discussion}

Recently, we have reported that Pd(II) complexes can be employed as versatile recognition units in sensor arrays for peptides ${ }^{10}$ or oligodeoxynucleotides. ${ }^{11}$ During the course of these studies we observed that $\left[\mathrm{Pd}\left(\mathrm{NO}_{3}\right)_{2}\right.$ (bipy)] (1) displays a high affinity for PPi. This prompted us to investigate whether complex 1 could be used to create a chemosensor for this anion.

In a first set of experiments we investigated the complexation of PPi to the Pd complex in more detail. A buffered aqueous solution (25 mM HEPES buffer, pH 7.0) of complex $1(25 \mu \mathrm{M})$ displays absorptions in the UV region of the spectrum with maxima at $\lambda=$ 307 and $316 \mathrm{~nm}$. In the presence of increasing amounts of $\mathrm{Na}_{4} \mathrm{P}_{2} \mathrm{O}_{7}$ $(0-100 \mu \mathrm{M})$, the absorption at $\lambda=320 \mathrm{~nm}$ constantly decreases, whereas the band at $\lambda=310 \mathrm{~nm}$ first decreases and then increases (Fig. 1).

The absorption at $\lambda=310 \mathrm{~nm}$ shows a minimum for a $\mathrm{Pd} / \mathrm{PPi}$ ratio of $\sim 2: 1$. This result suggests that a dinuclear complex is formed at low PPi concentrations, which is then converted into

${ }^{a}$ State Key Laboratory of Bioreactor Engineering and Shanghai Key Laboratory of Chemical Biology, School of Pharmacy, East China University of Science and Technology, 200237, Shanghai, China

${ }^{b}$ Institut des Sciences et Ingénierie Chimiques, École Polytechnique Fédérale de Lausanne (EPFL), 1015, Lausanne,Switzerland.E-mail:kay.severin@, epfl.ch

$\dagger$ CCDC reference number 776083. For crystallographic data in CIF or other electronic format see DOI: $10.1039 / \mathrm{c} 0 \mathrm{dt} 00434 \mathrm{k}$
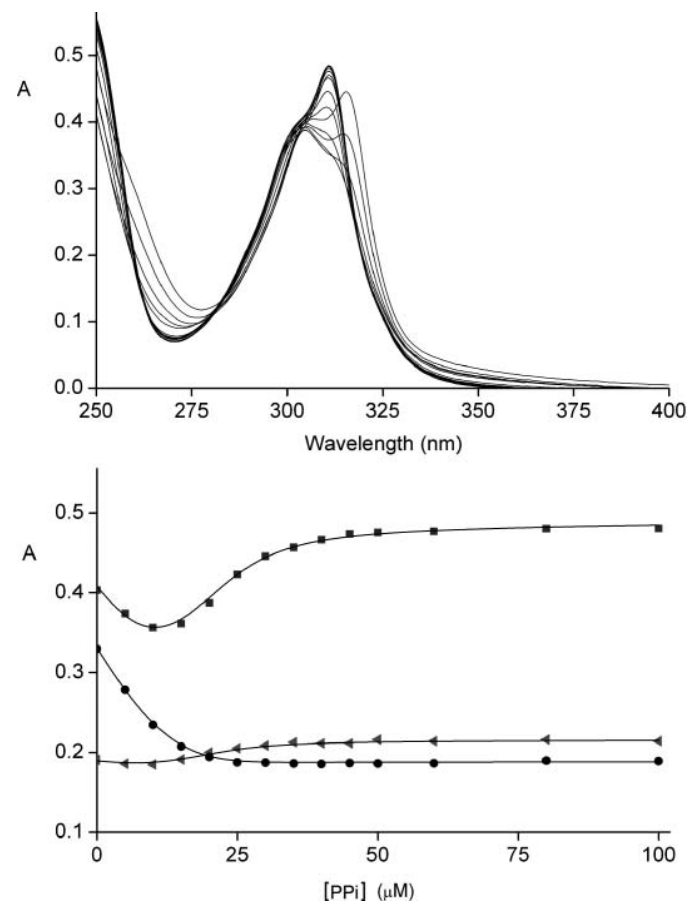

Fig. 1 Top: absorption spectra of solutions containing the palladium complex $1(25 \mu \mathrm{M})$ and different amounts of $\mathrm{PPi}(0-100 \mu \mathrm{M})$. The spectra were recorded in aqueous HEPES buffer solution $(25 \mathrm{mM}, \mathrm{pH} 7.0)$ after equilibration. Bottom: variation in absorbance at $\lambda=290(\varangle), 310$ (ם) and $320 \mathrm{~nm}(\bullet)$. The lines represent the best fit to the model discussed in the main text.

a mononuclear adduct at higher PPi concentrations (Scheme 1). Accordingly, it is possible to fit the absorption data to a model that involves 2:1 and 1:1 complexes (Fig. 1). The following binding constants were derived from the fitting procedure: $K_{1}=$ $3.4( \pm 0.3) \cdot 10^{6} \mathrm{M}^{-1}$ and $K_{2}=4.2( \pm 0.4) \cdot 10^{4} \mathrm{M}^{-1}$. Additional evidence for the formation of a dinuclear Pd-PPi complex was obtained from a Job plot (Fig. 2). The absorbance at $\lambda=320 \mathrm{~nm}$ was recorded for solutions with different $[\mathrm{Pd}] /([\mathrm{Pd}]+[\mathrm{PPi}])$ ratios and a maximum was found for $[\mathrm{Pd}] /([\mathrm{Pd}]+[\mathrm{PPi}]) \sim 0.66$ (Fig. 2).

For the 1:1 complex, it is likely that PPi acts as a bidentate chelate ligand, replacing the two weakly bound ligands opposite to the bipy N-donor ligand. ${ }^{12}$ For the $2: 1$ complex, single crystals were obtained by slow evaporation of an aqueous solution and its structure was unambiguously determined by X-ray diffraction 


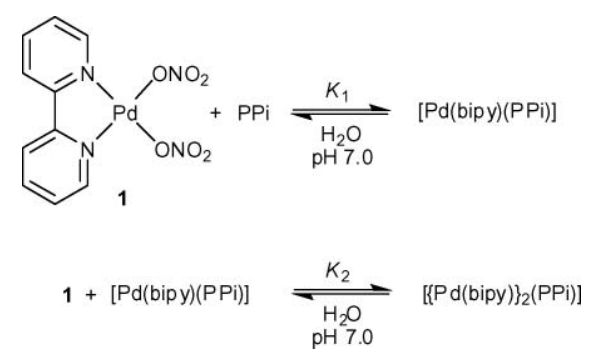

Scheme 1 Complexation of PPi to the Pd complex 1. The formulas given for the PPi complexes indicate only the stoichiometry; charges, solvation and counter ions are neglected.

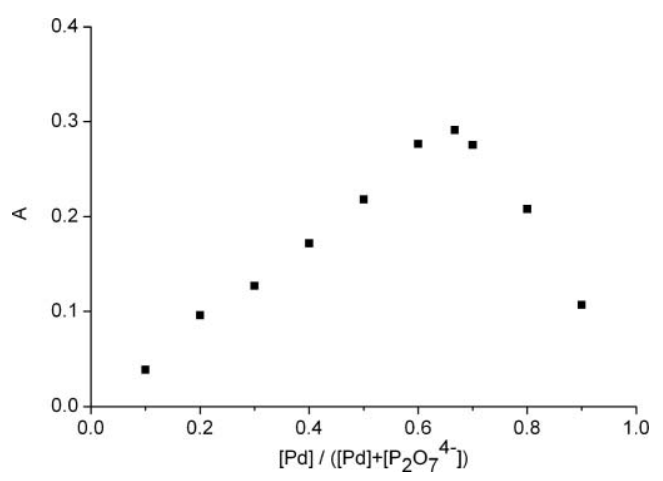

Fig. 2 Job plot for the binding between complex $\left[\mathrm{Pd}\left(\mathrm{NO}_{3}\right)_{2}\right.$ (bipy)] and $\mathrm{PPi}$. The data were obtained by recording the absorbance at $320 \mathrm{~nm}$ of solutions (25 mM HEPES buffer, $\mathrm{pH}$ 7.0) containing different ratios of Pd complex and $\mathrm{PPi}\left(\left[\mathrm{Pd}+\mathrm{P}_{2} \mathrm{O}_{7}{ }^{4-}\right]_{\text {total }}=100 \mu \mathrm{M}\right)$.

analysis. The solid-state structure of the complex is shown in Fig. 3. The structure features two $\mathrm{Pd}$ (bipy) units connected by a bridging $\mu-O, O^{\prime}, O^{\prime \prime}, O^{\prime \prime \prime}$-PPi chelate ligand, similar to that observed for the dinuclear $\mathrm{Pt}(\mathrm{II})$ complex $\left[\{\mathrm{Pt}(\mathrm{dach})\}_{2}\left(\mathrm{P}_{2} \mathrm{O}_{7}\right)\right]$ $($ dach $=$ trans-1,2-diaminocyclohexane $) .{ }^{13}$ The two bipy ligands are parallel and slightly off-set from one another, with a mean plane-to-plane distance of c.a. $3.7 \AA$, typical of $\pi-\pi$ stacking interactions. Similar interactions propagate throughout the crystal, with adjacent molecules forming one-dimensional columns along the crystallographic $c$-axis. The asymmetric unit also features six water molecules, which form a network of $\mathrm{O}-\mathrm{H}_{\text {water }} \cdots \mathrm{O}_{\mathrm{PPi}}$ hydrogen bonds linking adjacent columns.

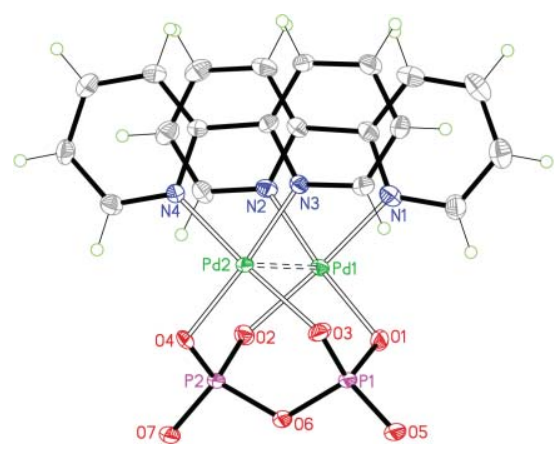

Fig. 3 Solid-state structure of $\left[\{\mathrm{Pd}(\text { bipy })\}_{2}(\mathrm{PPi})\right]$. Thermal ellipsoids are shown at $50 \%$ probability level. Selected bond lengths: Pd1-Pd2

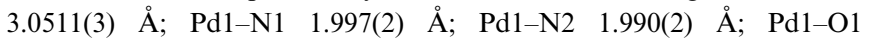

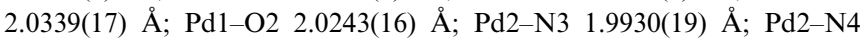

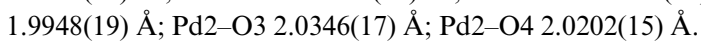

Having established that complex 1 displays high affinity for $\mathrm{PPi}$ in neutral aqueous solution, we were looking for a means to convert the binding of PPi into an optical signal. A priori, two strategies could be envisioned: (1) the covalent attachment of a chromophore or fluorophore to the bipyridyl ligand, or (2) the utilization of an indicator displacement assay (IDA). ${ }^{14}$ The latter strategy appeared more appealing because it is typically very easy to implement (the sensor is generated in situ by mixing the receptor with the indicator).

For the creation of an IDA for PPi we needed an indicator which binds to complex $\mathbf{1}$ with a similar affinity as PPi. Furthermore, the bound and the free indicator should have different optical properties. We found that Methylcalcein blue (MCB) can be employed for this purpose. MCB is a commonly available and water-soluble fluorescent dye which is known to bind metal cations such as $\mathrm{Cu}$ (II) and $\mathrm{Ca}(\mathrm{II}){ }^{15}$

Titration experiments with a fixed concentration of MCB $(20 \mu \mathrm{M})$ and variable amounts of complex $1(0-360 \mu \mathrm{M})$ resulted in almost complete quenching for a $\mathrm{Pd} / \mathrm{MCB}$ ratio of $\sim 18: 1$. A Stern-Volmer plot showing the initial $\left(I_{0}\right)$ to observed $\left(I_{\mathrm{F}}\right)$ fluorescence intensity ratio as a function of [1 $]_{\mathrm{tot}}$ is given in Fig. 4. The relative fluorescence intensity of $\mathrm{MCB}$ decreases linearly up to concentrations of $[\mathbf{1}]_{\text {tot }}=75 \mu \mathrm{M}$ and the data can be satisfyingly fitted to a model which takes into account static quenching according to $I_{0} / I_{\mathrm{F}}=\left(1+K_{\mathrm{s}} \cdot[1]_{\mathrm{tot}}\right)$, where $K_{\mathrm{s}}$ is the static quenching constant. Best fits gave $K_{\mathrm{s}}=2.07( \pm 0.5) \cdot 10^{4} \mathrm{M}^{-1}$, indicating that the fluorophore complexes to 1 with a binding constant of $\log K=\log K_{\mathrm{s}} \approx 4.3$. For $[1]_{\mathrm{tot}}>100 \mu \mathrm{M}$ a deviation from linearity emerges, indicating the on-set of possible dynamic quenching processes. The implied ground-state complex, however, was evidenced by UV/vis spectroscopy (data not shown); spectral changes observed on titrating 1 into a solution of MCB $(20 \mu \mathrm{M})$
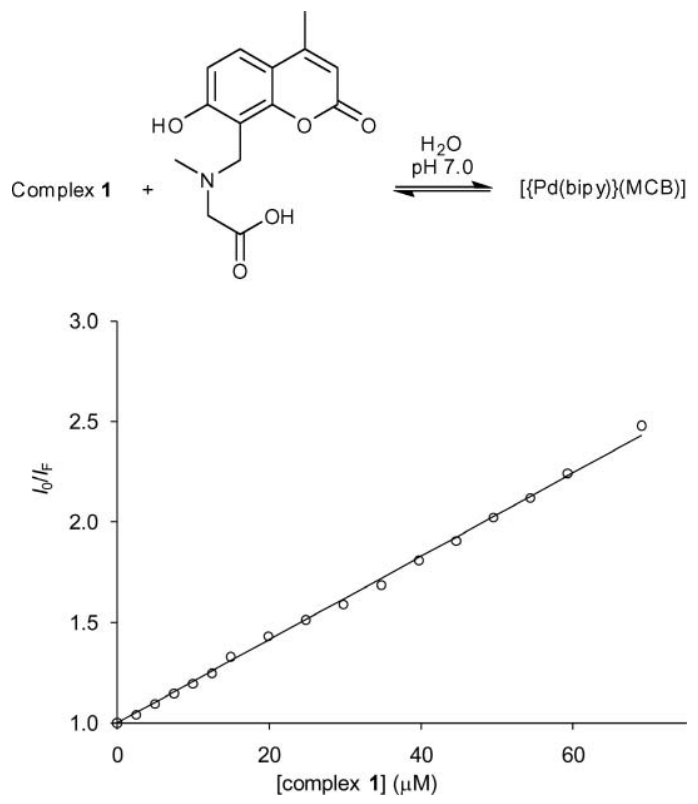

Fig. 4 Stern-Volmer plot showing fluorescence quenching of $\mathrm{MCB}$ $(20 \mu \mathrm{M})$ by complex $1\left(0-360 \mu \mathrm{M}, \lambda_{\mathrm{ex}}=410 \mathrm{~nm}, \lambda_{\mathrm{em}}=440 \mathrm{~nm}\right)$. The spectra were recorded in aqueous HEPES buffer solution ( $25 \mathrm{mM}, \mathrm{pH} 7.0$ ). The line represents the best fit to the model discussed in the main text. The formulas indicate only the stoichiometry; charges, solvation and counter ions are neglected. 
could be modelled by taking into account three absorbing species and least-squares fitting of the data to a $1: 1$ binding isotherm gave $\log K_{1}=4.35(5)$, which compares favorably with the SternVolmer quenching studies. Taken together, these data clearly show that MCB binds to the Pd complex in water, with substantial attenuation of its fluorescence emission.

Next, we examined whether a mixture of complex 1 and MCB could be used as a chemosensing ensemble for the detection of PPi. A buffered aqueous solution of MCB $(50 \mu \mathrm{M})$ and complex $1(500 \mu \mathrm{M})$ showed only weak fluorescence when excited at $\lambda=$ $410 \mathrm{~nm}$. The use of a 10-fold excess of complex 1 ensures that the fluorophore is in its fully bound and non-emissive (vide supra) state. In the presence of PPi $(400 \mu \mathrm{M})$, however, the original fluorescence of MCB was fully recovered and a strong emission at $\lambda=440 \mathrm{~nm}$ was observed (Fig. 5). The sensing ensemble displays a very good selectivity for PPi over other simple anions (Fig. 5). This was demonstrated by recording the fluorescence spectra of solutions containing a large excess of fluoride, chloride, bromide, dihydrogenphosphate, chlorate, sulfate, acetate, bicarbonate, nitrate and salicylate $(1.0 \mathrm{mM}$, added in the form of their sodium salts). Only the addition of $\mathrm{NaH}_{2} \mathrm{PO}_{4}$ and $\mathrm{NaClO}_{4}$ resulted in a minor increase in fluorescence (Fig. 5).
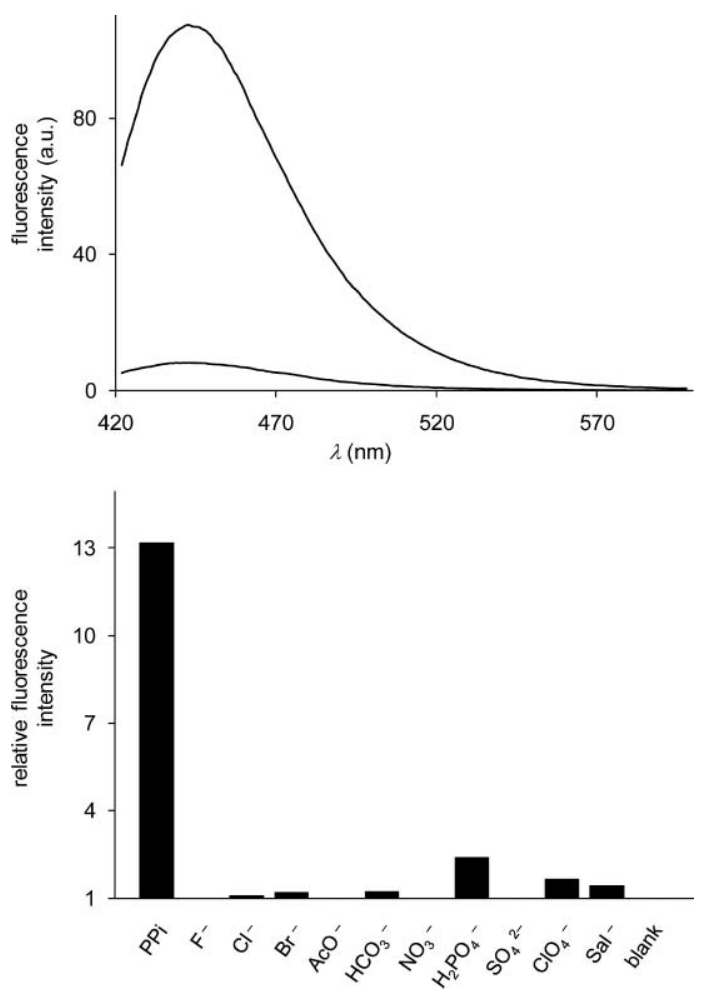

Fig. 5 Top: fluorescence emission spectra of sensing ensemble comprised of complex $1(500 \mu \mathrm{M})$ and $\mathrm{MCB}(50 \mu \mathrm{M})$ in the absence and in the presence of $\mathrm{Na}_{4} \mathrm{P}_{2} \mathrm{O}_{7}(400 \mu \mathrm{M})$. Bottom: relative fluorescence emission at $440 \mathrm{~nm}$ $\left(\lambda_{\text {ex }}=410 \mathrm{~nm}\right)$ in the presence of $\mathrm{Na}_{4} \mathrm{P}_{2} \mathrm{O}_{7}(400 \mu \mathrm{M})$ or $\mathrm{NaF}, \mathrm{NaCl}, \mathrm{NaBr}$, $\mathrm{NaOAc}, \mathrm{NaHCO}_{3}, \mathrm{NaNO}_{3}, \mathrm{NaH}_{2} \mathrm{PO}_{4}, \mathrm{Na}_{2} \mathrm{SO}_{4}, \mathrm{NaClO}_{4}$, and sodium salicylate (1.0 mM each). The spectra were recorded in aqueous HEPES buffer solution ( $25 \mathrm{mM}, \mathrm{pH} 7.0)$ after equilibration.

We have also measured the fluorescence of samples containing a variable PPi concentration of 0 to $600 \mu \mathrm{M}$ (Fig. 6). The sigmoidal shaped curve reflects the fact that both $1: 1$ and $2: 1$ complexes

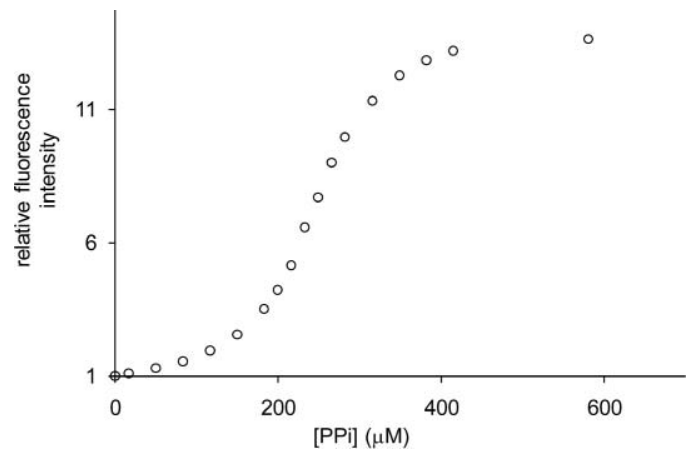

Fig. 6 Relative fluorescence emission at $440 \mathrm{~nm}\left(\lambda_{\mathrm{ex}}=410 \mathrm{~nm}\right)$ of the sensing ensemble comprised of complex $1(500 \mu \mathrm{M})$ and MCB $(50 \mu \mathrm{M})$ in the presence of variable amounts of $\mathrm{Na}_{4} \mathrm{P}_{2} \mathrm{O}_{7}(0-600 \mu \mathrm{M})$. The spectra were recorded in aqueous HEPES buffer solution $(25 \mathrm{mM}, \mathrm{pH} 7.0)$ after equilibration.

of 1-PPi are formed during the titration. The resulting data can be used as a calibration curve for the sensing of PPi at low to mid micromolar concentrations, with a dynamic range of approximately $50-450 \mu \mathrm{M}$ and an estimated detection limit of c.a. $50 \mu \mathrm{M}$ for quantitative determination.

\section{Conclusions}

We have described a chemosensing ensemble comprised of the Pd complex 1 and the fluorescent dye MCB. The addition of PPi gives a strong turn-on fluorescence signal, which allows the detection of PPi in the low micromolar concentration range. The selectivity for PPi over inorganic anions such as chloride, phosphate, or bicarbonate is very good. Contrary to some of the $\mathrm{Zn}$-based sensors described previously, ${ }^{4}$ our system cannot be used to detect PPi in a biological environment, because the Pd complex will bind to peptides ${ }^{10}$ and oligonucleotides. ${ }^{11}$ For the detection of PPi in an abiotic environment, however, our sensor should be well suited. An important advantage from a practical point of view is the fact that the sensor can be obtained in situ by mixing easily accessible compounds.

\section{Experimental}

\section{General}

Methylcalcein blue (MCB) (Sigma-Aldrich), 4-(2-hydroxyethyl)piperazine-1-ethane-sulfonic acid (HEPES) (Sigma-Aldrich), and sodium pyrophosphate decahydrate (Acros) were purchased and used as received. The palladium complex $\left[\mathrm{Pd}\left(\mathrm{NO}_{3}\right)_{2}(\right.$ bipy $\left.)\right](\mathbf{1})$ was prepared as described in the literature. ${ }^{16}$ HEPES buffer solution (25 mM, pH 7.0) was prepared with bidistilled water. Stock solutions of all compounds were prepared in HEPES buffer (25 mM, pH 7.0) and stored in the refrigerator. UV/Vis spectra were recorded at room temperature with a Perkin Elmer Lambda 40 spectrometer. Fluorescence measurements were recorded at $25^{\circ} \mathrm{C}$ on a Varian Cary Eclipse spectrophotometer equipped with a thermostatted cell holder. 


\section{Spectrophotometric titration of complex 1 and PPi}

Stock solutions of complex 1 and PPi in HEPES buffer $(25 \mathrm{mM}$, $\mathrm{pH}$ 7.0) were used to prepare a series of solutions with a constant Pd concentration of $25 \mu \mathrm{M}$ and a variable concentration of PPi. The final anion concentrations were $0-100 \mu \mathrm{M}$. After equilibration at room temperature in the dark, the absorption spectra were recorded in the range $250-400 \mathrm{~nm}$ (a kinetic study with $25 \mu \mathrm{M}$ PPi and $25 \mu \mathrm{M}$ of complex 1 showed that the equilibrium is reached within $5 \mathrm{~min}$ ). The resulting data were fitted to a model involving $1: 1$ and $2: 1$ complexes of Pd and PPi. The calculations

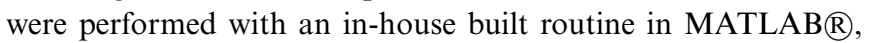
which implements evolving factor analysis and a Newton-Gauss multi-non-linear least squares fitting algorithm. ${ }^{17,18}$ The standard deviations for the fitted parameters $(K)$ were estimated using the sum-of-squared residuals and inverted curvature matrices as obtained from the iterative fitting processes. To take into account pipetting and/or concentration errors in the stock solutions, the minimum error was set at $10 \%$.

\section{Fluorimetric and spectrophotometric titrations of complex 1 and MCB}

Stock solutions of complex 1 and MCB in HEPES buffer $(25 \mathrm{mM}$, $\mathrm{pH}$ 7.0) were used to prepare a series of solutions with a constant MCB concentration $(20 \mu \mathrm{M})$ and a variable concentration of complex $1(0-400 \mu \mathrm{M})$. The fluorescence $\left(\lambda_{\mathrm{ex}}=410 \mathrm{~nm}, \lambda_{\mathrm{em}}=\right.$ $440 \mathrm{~nm})$ and $\mathrm{UV} / \mathrm{Vis}(325<\lambda<500 \mathrm{~nm})$ spectra were measured after equilibration at room temperature in the dark (a kinetic study showed that the equilibrium is reached within $5 \mathrm{~min}$ ). Data fitting was carried out as described above, or in the main text.

\section{Sensing of PPi}

Concentrated solutions of PPi were added in $1 \mu \mathrm{L}$ increments to a solution $(3 \mathrm{~mL})$ containing complex $1(500 \mu \mathrm{M})$ and $\mathrm{MCB}(50 \mu \mathrm{M})$ in HEPES buffer ( $25 \mathrm{mM}, \mathrm{pH} 7.0)$. The fluorescence spectra $\left(\lambda_{\mathrm{ex}}=410 \mathrm{~nm}, \lambda_{\mathrm{em}}=440 \mathrm{~nm}\right.$ ) were measured after equilibration for $5 \mathrm{~min}$ at room temperature in the dark. Any changes in concentration of $\mathbf{1}$ and $\mathrm{MCB}$ were sufficiently small as to be negligible $(<1 \%)$. Control experiments with other anions were performed with $\mathrm{NaCl}, \mathrm{NaBr}, \mathrm{NaF}, \mathrm{NaH}_{2} \mathrm{PO}_{4}, \mathrm{NaClO}_{4}, \mathrm{Na}_{2} \mathrm{SO}_{4}$, $\mathrm{NaOAc}, \mathrm{NaHCO}_{3}, \mathrm{NaNO}_{3}$ and sodium salicylate (final conc.: $1.0 \mathrm{mM})$.

\section{Crystallography}

Diffraction intensities were measured at 100(2) K on a Bruker APEX II diffractometer equipped with a graphite monochromated Mo-K $\alpha$ radiation source. Data were reduced using EvalCCD ${ }^{19}$ and corrected for absorption using the semi-empirical method. ${ }^{20}$ Structure solution, refinement and geometric calculations were performed with SHELX. ${ }^{21}$ Crystallographic data for $\left[\{\mathrm{Pd}(\text { bipy })\}_{2}(\mathrm{PPi})\right] \cdot 6 \mathrm{H}_{2} \mathrm{O}: M=807.20$, Monoclinic $C c, a=$ 16.583(3), $b=12.6047(15), c=13.4967(6) \AA, b=105.850(8)^{\circ}, V=$ $2713.8(5) \AA^{3}, Z=4 ; \rho_{\mathrm{c}}=1.976 \mathrm{Mg} \mathrm{m}^{-3}, F(000)=1608$; crystal dimensions $0.47 \times 0.27 \times 0.24 \mathrm{~mm}^{3} ; \mu($ Mo-K $\alpha)=1.516 \mathrm{~mm}^{-1}$, $T=100 \mathrm{~K}$. A total of 21969 reflections were measured in the range $3.23 \leq \theta \leq 27.50^{\circ}$ ( $h \mathrm{kl}$ range indices: $-21 \leq h \leq 21,-16 \leq$ $k \leq 16,-1 \overline{7} \leq \bar{l} \leq 17), 5829$ unique reflections $\left(R_{\mathrm{int}}=0.0265\right)$.
The structure was refined on $F^{2}$ to $R_{\mathrm{w}}=0.0164, R=0.0160$ (5764 reflections with $I>2 \sigma(I)$ ) and GOF $=1.081$ on $F^{2}$ for 407 refined parameters and 51 restraints. The absolute structure (Flack) parameter converged to 0.001(11). Largest peak and hole 0.329 and $-0.494 \mathrm{e}^{-3}$. CCDC 776083 .

\section{Acknowledgements}

The work was supported by the Swiss National Science Foundation, the China Scholarship Council (CSC), and by the EPFL.

\section{References}

1 J. K. Heinonen, Biological Role of Inorganic Pyrophosphate, Kluwer Academic Publishers, Norwell, 2001.

2 (a) M. T. Averbuch-Pouchot and A. Durif, Topics in Phosphate Chemistry, World Scientific Publishing Co. Ptv. Ltd., Singapore, 1996; (b) R. A. Molins, Phosphates in Food, CRC Press. Inc., Boca Raton, 1991.

3 S. K. Kim, D. H. Lee, J.-I. Hong and J. Yoon, Acc. Chem. Res., 2009, 42, 23-31.

4 (a) C. Park and J.-I. Hong, Tetrahedron Lett., 2010, 51, 1960-1962; (b) X.-h. Huang, Y. Lu, Y.-b. He and Z.-h. Chen, Eur. J. Org. Chem., 2010, 1921-1927; (c) S. Khatua, S. H. Choi, J. Lee, K. Kim, Y. Do and D. G. Churchill, Inorg. Chem., 2009, 48, 2993-2999; (d) M. K. Coggins, A. M. Parker, A. Mangalum, G. A. Galdamez and R. C. Smith, Eur. J. Org. Chem., 2009, 343-348; (e) L. Tang, Y. Li, H. Zhang, Z. Guo and J. Qian, Tetrahedron Lett., 2009, 50, 6844-6847; $(f)$ G. Su, Z. Liu, Z. Xie, F. Qian, W. He and Z. Guo, Dalton Trans., 2009, 7888-7890; $(g)$ G. Ambrosi, M. Formica, V. Fusi, L. Giorgi, A. Guerri, E. Macedi, M. Micheloni, P. Paoli, R. Pontellini and P. Rossi, Inorg. Chem., 2009, 48, 5901-5912; (h) J. V. Carolan, S. J. Butler and K. A. Jolliffe, J. Org. Chem., 2009, 74, 2992-2996; (i) A. Nonaka, S. Horie, T. D. James and Y. Kubo, Org. Biomol. Chem., 2008, 6, 3621-3625; (j) D.-H. Lee and J.-I. Hong, Bull. Korean Chem. Soc., 2008, 29, 497498; (k) L. Rodríguez, J. C. Lima, A. J. Parola, F. Pina, R. Meitz, R. Aucejo, E. Garcia-España, J. M. Llinares, C. Soriano and J. Alarcón, Inorg. Chem., 2008, 47, 6173-6183; (l) D. H. Lee, S. Y. Kim and J.-I. Hong, Tetrahedron Lett., 2007, 48, 4477-4480; $(m)$ X. Zhao, Y. Liu and K. S. Schanze, Chem. Commun., 2007, 2914-2916; (n) J. H. Lee, J. Park, M. S. Lah, J. Chin and J.-I. Hong, Org. Lett., 2007, 9, 37293731; (o) H. N. Lee, Z. Xu, S. K. Kim, K. M. K. Swamy, Y. Kim, S.-J. Kim and J. Yoon, J. Am. Chem. Soc., 2007, 129, 3828-3829; (p) H. N. Lee, K. M. K. Swamy, S. K. Kim, J.-Y. Kwon, Y. Kim, S.-J. Kim, Y. J. Yoon and J. Yoon, Org. Lett., 2007, 9, 243-246; (q) X. Peng, Y. Xu, S. Sun, Y. Wu and J. Fan, Org. Biomol. Chem., 2007, 5, 226-228; $(r)$ M. J. McDonough, A. J. Reynolds, W. Y. G. Lee and K. A. Jolliffe, Chem. Commun., 2006, 2971-2973; (s) H. K. Cho, D. H. Lee and J.-I. Hong, Chem. Commun., 2005, 1690-1692; $(t)$ D. H. Lee, S. Y. Kim and J.-I. Hong, Angew. Chem., Int. Ed., 2004, 43, 4777-4780; (u) D. H. Lee, J. H. Im, S. U. Son, Y. K. Chung and J.-I. Hong, J. Am. Chem. Soc., 2003, 125, 7752-7753.

5 (a) S. Watchasit, A. Kaowliew, C. Suksai, T. Tuntulani, W. Ngeontae and C. Pakawatchai, Tetrahedron Lett., 2010, 51, 3398-3402; (b) Z. Guo, W. Zhu and H. Tian, Macromolecules, 2010, 43, 739-744; (c) M. J. Kim, K. M. K. Swamy, K. M. Lee, A. R. Jagdale, Y. Kim, S.-J. Kim, K. H. Yoo and J. Yoon, Chem. Commun., 2009, 7215-7217; (d) S. Y. Kim and J.-I. Hong, Tetrahedron Lett., 2009, 50, 1951-1953; (e) X. Huang, Z. Guo, W. Zhu, Y. Xie and H. Tian, Chem. Commun., 2008, 5143-5145; $(f)$ Y. J. Jang, E. J. Jun, Y. J. Lee, Y. S. Kim, J. S. Kim and J. Yoon, J. Org. Chem., 2005, 70, 9603-9606; $(g)$ L. Fabbrizzi, N. Marcotte, F. Stomeo and A. Taglietti, Angew. Chem., Int. Ed., 2002, 41, 3811-3814.

6 S. Mizukami, T. Nagano, Y. Urano, A. Odani and K. Kikuchi, J. Am. Chem. Soc., 2002, 124, 3920-3925.

7 K. M. K. Swamy, S. K. Kwon, H. N. Lee, S. M. S. Kumar, J. S. Kim and J. Yoon, Tetrahedron Lett., 2007, 48, 8683-8686.

8 N. Shao, J. Jin, G. Wang, Y. Zhang, R. Yang and J. Yuan, Chem. Commun., 2008, 1127-1129. 
9 C. M. G. dos Santos and T. Gunnlaugsson, Dalton Trans., 2009, 47124721.

10 S. Rochat, J. Gao, X. Qian, F. Zaubitzer and K. Severin, Chem.-Eur. J., 2010, 16, 104-113.

11 J. Gao, A. Granzhan, X. Qian, and K. Severin, Chem. Commun., 2010, 10.1039/c0cc00389a.

12 O. F. Ikotun, N. Marino, P. E. Kruger, M. Julve and R. P. Doyle, Coord. Chem. Rev., 2010, 254, 890-915.

13 R. J. Mishur, C. Zheng, T. M. Gilbert and R. N. Bose, Inorg. Chem., 2008, 47, 7972-7982.

14 B. T. Nguyen and E. V. Anslyn, Coord. Chem. Rev., 2006, 250, $3118-$ 3127.

15 G. Huitink and H. Diehl, Talanta, 1974, 21, 11931202.
16 S. Wimmer, P. Castan, F. L. Wimmer and N. P. Johnson, J. Chem. Soc., Dalton Trans., 1989, 403-412.

17 M. Maeder and Y.-M. Neuhold, in Practical Data Analysis in Chemistry, ed. S. Rutan and B. Walczak, Elsevier Publishing Co, Amsterdam, 2007.

18 (a) H. Gampp, M. Maeder, C. J. Meyer and A. D. Zuberbühler, Talanta, 1985, 32, 1133-1139; (b) H. Gampp, M. Maeder, C. J. Meyer and A. D. Zuberbühler, Talanta, 1986, 33, 943-951.

19 A. J. M. Duisenberg, L. M. J. Kroon-Batenburg and A. M. M. Schreurs, J. Appl. Crystallogr., 2003, 36, 220-229.

20 R. H. Blessing, Acta Crystallogr., Sect. A: Found. Crystallogr., 1995, 51, 33-38.

21 SHELX, G. M. Sheldrick, Acta Crystallogr., Sect. A: Found. Crystallogr., 2008, 64, 112-122. 